WSRC-RP--92-974

DE93 006887
Key Words: LLRWDF

Dynamic Compaction Burial Grounds Criticality USQE

Retention: Lifetime

\title{
Criticality Assessment Of LLRWDF Closure (U)
}

Authors:

A. G. Sarrack, J. H. Weber, and N. D. Woody

October 6, 1992

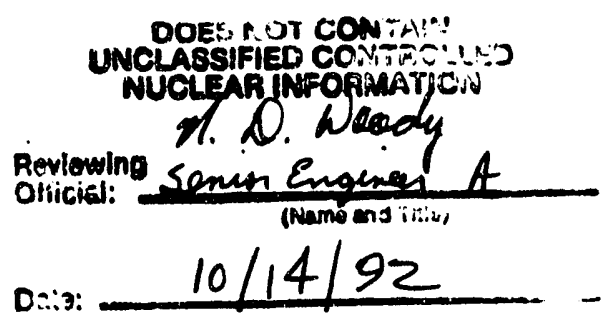

Westinghouse Savannah River Company Savannah River Technology Center Aiken, SC 29808

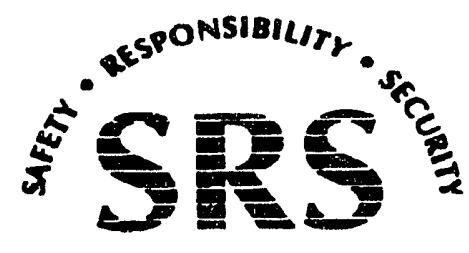

SAVANNAH RIVER SITE

PREPARED FOR THE U.S. DEPARTMENT OF ENERGY UNDER CONTRACT NOF P- 
Project:

Document:

Title:

Task:
LLRWDF Closure

WSRC-RP-92-974

Criticality Assessment of LLRWDF

Closure (U)

SRT-EAG-92-8001

\section{Approvals:}

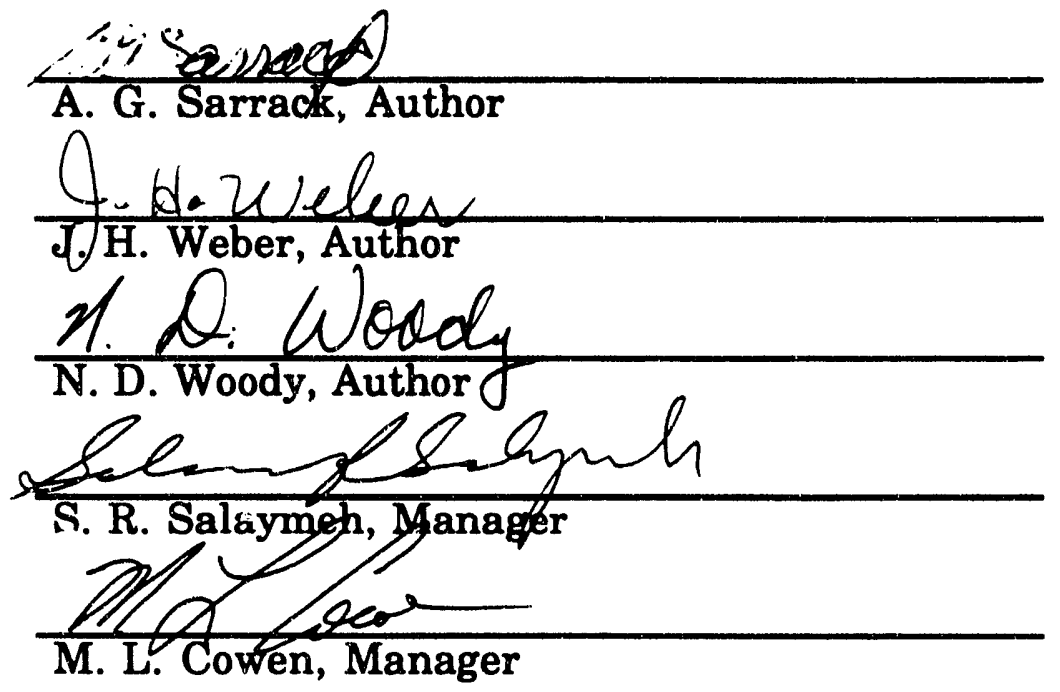

$\frac{10-14-92}{\text { Date: }}$

$\frac{10-14-92}{\text { Date: }}$ $\frac{10 / 14 / 22}{\text { Date }}$ $\frac{10 / 16 / 92}{\text { Date: }}$ $\frac{\text { so/16/92 }}{\text { Date: }}$ 


\begin{abstract}
During the operation of the Low Level Radioactive Waste Disposal Facility (LLRWDF), large amounts (greater than $100 \mathrm{~kg}$ ) of enriched uranium (EU) were buried. This EU came primarily from the closing and decontamination of the Naval Fuels Facility in the time period from 1987-89. Waste Management Operations (WMO) procedures were used to keep the EU boxes separated to prevent possible criticality during normal operation. Closure of the LLRWDF is currently being plannced, and waste stabilization by Dynamic Compaction (DC) is proposed. Dynamic compaction will crush the containers in the LLRWDF and result in changes in their geometry.

Research of the LLRWDF operations and record keeping practices have shown that the EU contents of trenches are known, but details of the arrangement of the contents cannot be proven. Reviews of the trench contents, combined with analysis of potential critical configurations, revealed that some portions of the LLRWDF can be expected to be free of criticality concerns while other sections have credible probabilities for the assembly of a critical mass, even in the uncompacted configuration. This will have an impact on the closure options and which trenches can be compacted.
\end{abstract}




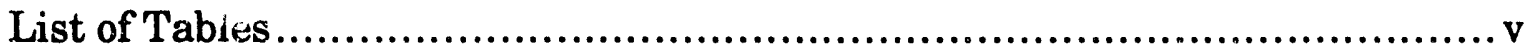

List of Figures..................................................................... vi

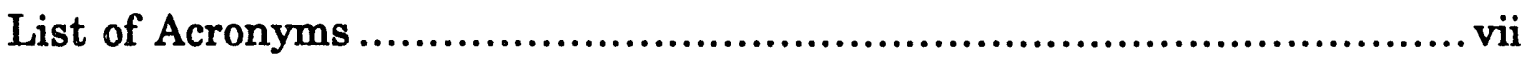

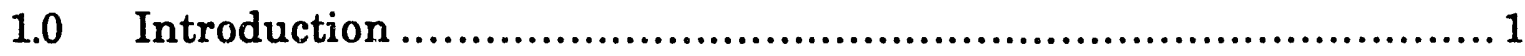

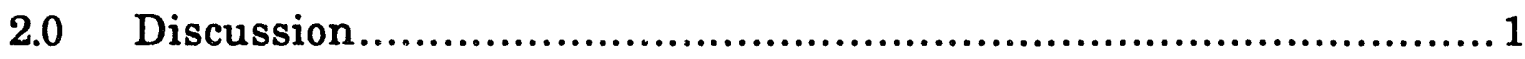

2.1 Administrative Controls For EU Burials ............................ 3

2.2 LLRWDF Burial Procedures ....................................... 4

$2.3 \quad$ LLRWDF Burial Records..............................................13

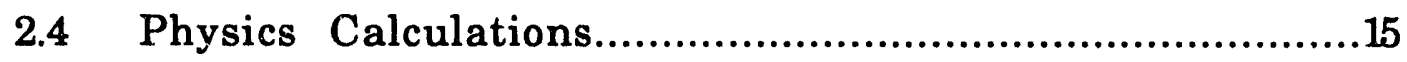

2.5 Statistical Assessment ............................................19

2.6 Special Considerations.............................................20

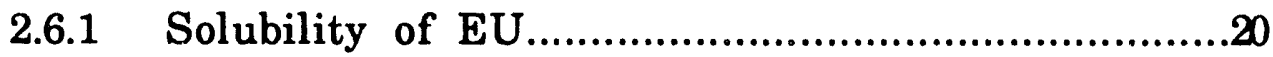

2.6.2 ELLT 2 Exclusions.......................................21

2.6.3 Flooding of ELLT 4.........................................21

2.6.4 DC Test Results...............................................21

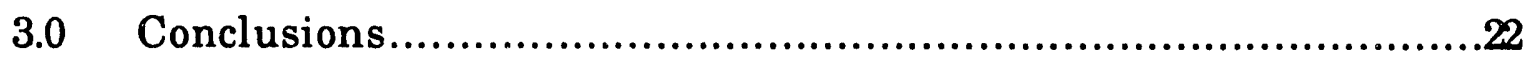

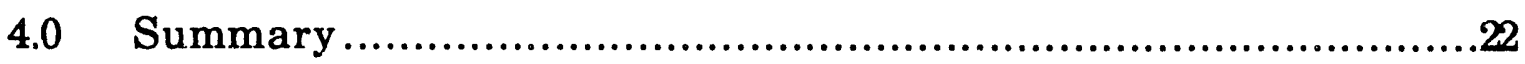

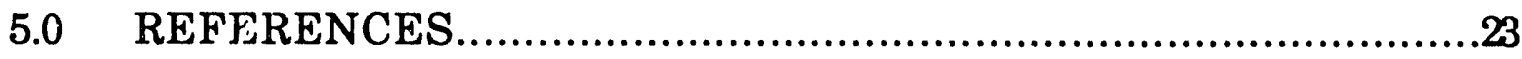

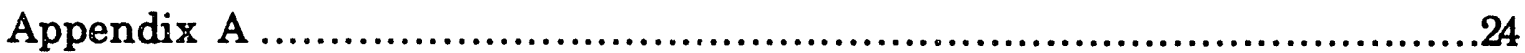




\section{LIST OF TABLES}

PAGE

Table 1. Summary of Filling History for ELLTs 2, 3, and 4...................4

Table 2. Sample COBRA data for ELLT 2 ...........................................14

Table 3. Sample COBRA data for ELLT 3.........................................14

Table 4. Sample COBRA data for ELLT 4 ...........................................15

Table 5. Summary Of U-235 Containers ......................................16

Table 6. Probability of Assembling EU Containers...............................20 


\section{LIST OF FIGURES}

PAGE

Figure 1. Burial Ground Complex - Known or Suspected Trenches and Facilities.............................................2

Figure 2. ELLT 2 and ELLT 3 Approximate Coordinates................ 5

Figure 3. ELLT 4 and Trench Area 1 Approximate Coordinates..........6

Figure 4. Trench Area 2 Approximate Coordinates.........................7

Figure 5. Trench Area 3 Approximate Coordinates.......................8

Figure 6. Trench Area 4-6 Approximate Coordinates ......................9

Figure 7. Additional Trenches; Approximate Coordinates...............10

Figure 8. Stair-Step Loading Pattern ..................................12

Figure 9. KENO Representation of Box Arrangement....................18

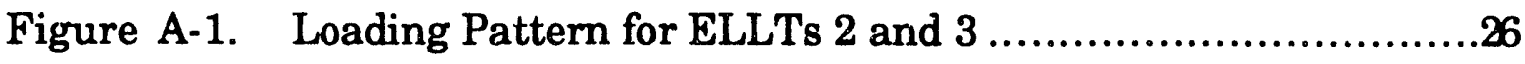

Figure A-2. Loading Pattern for ELLT 4 ....................................27 


\section{LIST OF ACRONYMS}

CAC Criticality Audit Committee

COBRA Computerized Burial Records Analysis

DC

Dynamic Compaction

ELLT

ER

Engineered Low Level Trench

EU

Environmental Restoration

GPR

Enriched Uranium

LLRWDF

Ground Penetrating Radar

RCRA

SAR

Low Level Radioactive Waste Disposal Facility

Resource Conservation and Recovery Act

USQ

USQE

Safety Analysis Report

Unreviewed Safety Question

Unreviewed Safety Question Evaluation

WMO

Waste Management Operations 


\subsection{INTRODUCTION}

This report contains a description of the criticality safety analysis performed as part of the Unreviewed Safety Question (USQ) Evaluation for closure of part of the nev burial ground, known as Building 643-7E. Specifically, the possibility of criticality during dynamic compaction of the Low Level Radioactive Waste Disposal Facility (LLRWDF) is assessed. Closure of the LLRWDF is required under the Resource Conservation and Recovery Act (RCRA). It involves stabilization of the waste followed by construction of a clay cap or geosynthetic membrane over the waste site to minimize ingression of water. The cap will be maintained over an effective 30 year lifetime.

Dynamic Compaction (DC) is the proposed activity for waste stabilization. DC consists of repeatedly dropping a massive weight, 20 tons or more, from a predetermined height to compact the waste within the LLirWDF. This helps to minimize future subsidence of the waste, thereby reducing the stress placed on the cap and hence the cap maintenance.

During the operation of the LLRWDF, large amounts (greater than $100 \mathrm{~kg}$ ) of enriched uranium (EU) were buried. This EU came primarily from the closing and decontamination of the Naval Fuels Facility in the time period from 1987-89. Waste Management Operations (WMO) procedures were used to keep the EU boxes separated to prevent possible criticality during normal operation. Dynamic compaction will crush the containers in the LLRWDF and result in changes in their geometry. The purpose of the USQ evaluation is to determine if the change in geometry or the migration of material from the containers could lead to an inadvertent criticality.

Research of the LLRWDF operations and record keeping practices have shown that the EU contents of trenches are known, but details of the arrangement of the contents cannot be proven. Reviews of the trench contents combined with analysis of potential critical configurations, revealed that some portions of the LLRWDF can be expected to be free of criticality concerns while other sections have credible probabilities for the assembly of a critical mass, even in the uncompacted configuration. Each portion of the analyses performed will be discussed herein.

\subsection{DISCUSSION}

A diagram of the burial ground is shown in Figure 1. The areas of interest within the LLRWDF are Engineered Low Level Trenches (ELLTs) 2-4 and 28 individual slit trenches. The ELLTs are large trenches, twenty feet deep, used for loading B-25 and B-12 boxes in a 4-high matrix. Some 55-gallon drums were placed on the edges of the ELLTs prior to bickfill, and other materials were buried, on occasion, at the ends of the ELL $\Gamma$ s. According to the COmputerized Burial Records Analysis (COBRA) records, the ELLTs were filled during the following time frames: 


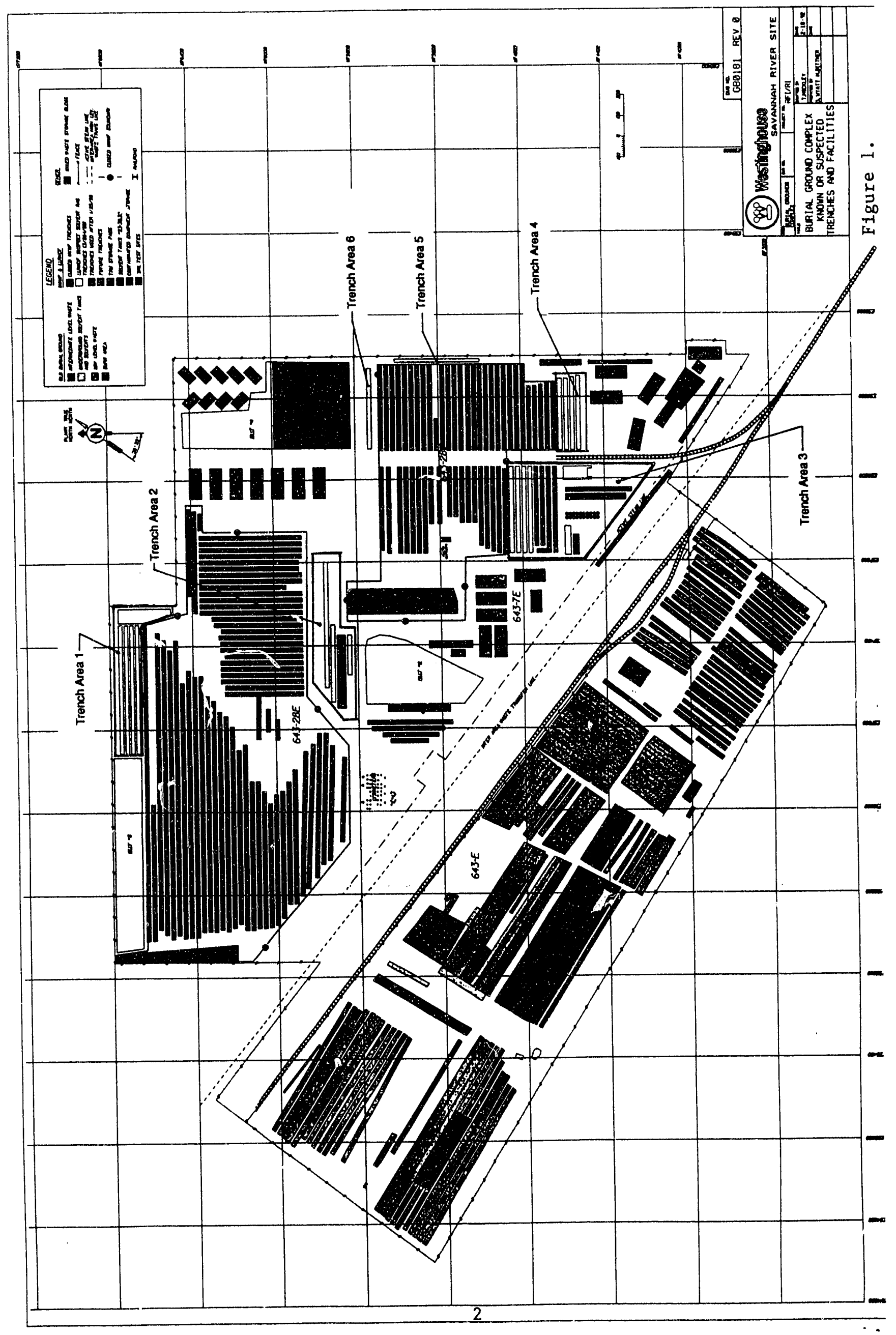



ELLT 2
ELLT 3
March '86 - January '89,
ELLT 4 July '87 - April '89, and
April '89 - present.

A summary of the filling history is given in Table 1. The significant item in the chronology is that ELLT 2 and ELLT 3 were both in use from July ' 87 to January '89. It was at this time that a large number of boxes containing significant amounts of EU were brought from Naval Fuels to the LLRWDF, and a deliberate attempt was made to separate EU boxes between the two ELLTs.

The slit trenches are typically twenty feet deep, twenty feet wide, 100 to 600 feet in length, and separated by $10-20$ feet of natural soil. The one exception to this design is trench E17.40, which is $250 \mathrm{ft}$. long and varies from 30 to 70 $\mathrm{ft}$. wide. The slit trenches are used to bury a variety of waste containers.

The approximate coordinates of the ELLTs and of individual trenches considered are shown in Figures 2 through 7. Identification of the actual trench coordinates will be determined by Environmental Restoration (ER) Assessments staff through the use of Ground Penetrating Radar (GPR). The GPR investigation is expecied to be complete in CY92. Minor changes in trench coordinates resulting from the GPR will not change the results or conclusions of this criticality study.

\section{Administrative Controls For EU Burials}

Th potential for criticality in the trenches is addressed in Sections 4.8.4.6, 5.1.3.1, and 5.3.3.1 of the Burial Ground Safety Analysis Report (SAR) (Reference 1). Section 4.8.4.6 describes minimum procedural restrictions for burying containers with EU. It states that EU burials must be placed, "...so that one box of non-enriched uranium separates the enriched uranium box on all sides." No reference is made to criticality studies from which the restrictions were derived, and no formal definitions are given for terms used, so the exact meaning of some key st tements is ambiguous.

The SAR was written with the expectations of handling waste with less than $20 \mathrm{~J} \mathrm{~g}$ of EU, with few exceptions. Therefore, criticality was considered extremely unlikely, and the criticality analysis performed was minimal. Section 5.3.3.1 states, ". only four incidents are recorded is the 200-Area Fault Tree Data Bank which resulted in significant quantiti's ( $>200 \mathrm{~g}$ ) of fissile material reaching the Burial Ground." Following the closure of the Naval Fuels facility, large amounts of EU $(>100 \mathrm{~kg})$ were buried, and COBRA records show more than one hundred individual containers each witi greater than $200 \mathrm{~g}$ of $\mathrm{EU}$.

Waste Management procedure DPSOL 643-G-2013-Q, Revision 15, Burying Waste Containing Enriched Uranium, specifies that, "Enriched uranium (Type 20) burials must be separated from all other shipments by a minimum 
Table 1. Summary of Filling History for ELLTs 2, 3, and 4

\begin{tabular}{|c|c|c|c|c|c|c|}
\hline & \multicolumn{2}{|c|}{ ELLT2 } & \multicolumn{2}{c|}{ ELLT 3 } & \multicolumn{2}{c|}{ ELLT 4 } \\
\hline Date & $\begin{array}{c}\text { \# of } \\
\text { Boxes }\end{array}$ & $\begin{array}{c}\text { Waste } \\
\text { Vol. } \\
(1000 \mathrm{ft} .3)\end{array}$ & $\begin{array}{c}\text { \# of } \\
\text { Boxes }\end{array}$ & $\begin{array}{c}\text { Waste } \\
\text { Vol. } \\
(1000 \mathrm{ft.} \text { 3 })\end{array}$ & $\begin{array}{c}\text { \# of } \\
\text { Boxes }\end{array}$ & $\begin{array}{c}\text { Waste } \\
\text { Vol. } \\
(1000 \mathrm{ft} .3)\end{array}$ \\
\hline $5 / 1 / 86$ & 872 & 83 & & & & \\
\hline $1 / 1 / 87$ & 7,175 & 659 & & & & \\
\hline $7 / 1 / 87$ & 12,217 & 1,116 & & & & \\
\hline $4 / 1 / 88$ & 12,822 & 1,181 & 5,602 & 505 & & \\
\hline $2 / 1 / 89$ & 14,672 & 1,354 & 12,432 & 1,150 & & \\
\hline $4 / 1 / 89$ & 14,673 & 1,355 & 13,738 & 1,267 & & \\
\hline $8 / 1 / 89$ & 14,676 & 1,356 & 13,987 & 1,290 & 2,183 & 199 \\
\hline $5 / 1 / 92$ & 14,676 & 1,356 & 13,987 & 1,290 & 19,266 & 1,759 \\
\hline
\end{tabular}

of 3 horizontal feet of earth or $1 \mathrm{~B}-25$ box for engineered low level trench (ELLT) operation when buried," and that, "No other shipment of enriched uranium will be buried in the same North-East coordinates." The procedure is written in a manner that leaves room for interpretation and affects how the waste is stored in both the ELLTs and the trenches. Discussions with Waste Management Operations personnel revealed that execution of the procedure may not meet the intent of the procedure or of the minimum restrictions of the Safety Analysis Report. As a result, the possibility exists for stacking EU boxes on top of one another.

\section{LLRWTF Burial Procedures}

When a container (i.e., box) is loaded into one of the trenches, it is assigned a location. A location is defined as the site grid coordinate assigned to a container by the WMO operator. This coordinate is obtained by looking at stakes along one of the trench sides. Ideally, the number of boxes in each location of a rectangular ELLT would be the number of boxes in a stack (typically 4) times the number of boxes in a row. Box locations are recorded on the burial slip and later entered into the COBRA database as a permanent record. The majority of locations are assigned in accordance with the following rules.

For a trench that runs North to South:

The East coordinate assigned to all containers is the trench center line. This is also the "name" given to a slit trench;

The North coordinate reflects the location of the container within the trench. The coordinate typically follows 5 foot increments. Since 


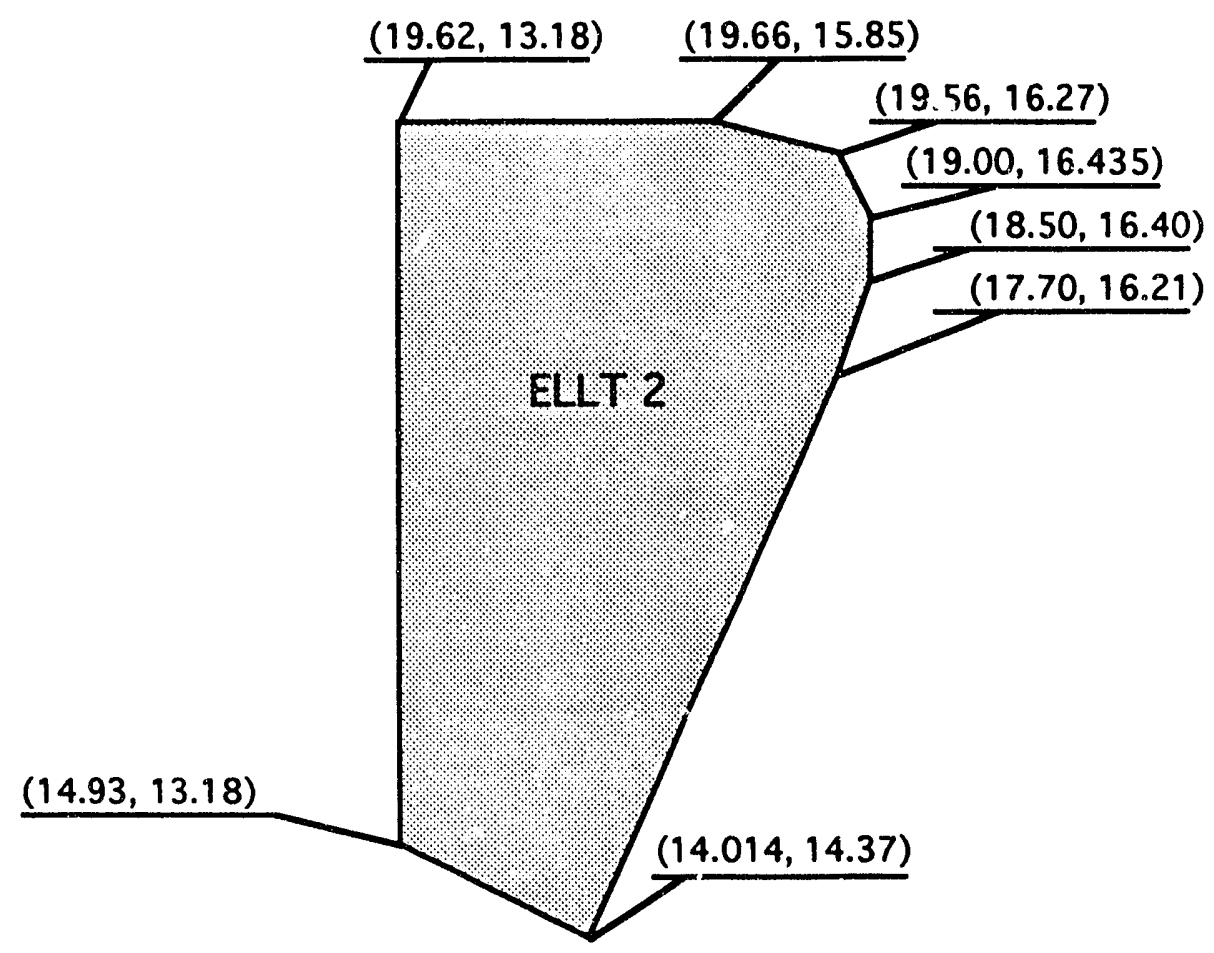

(North, East)

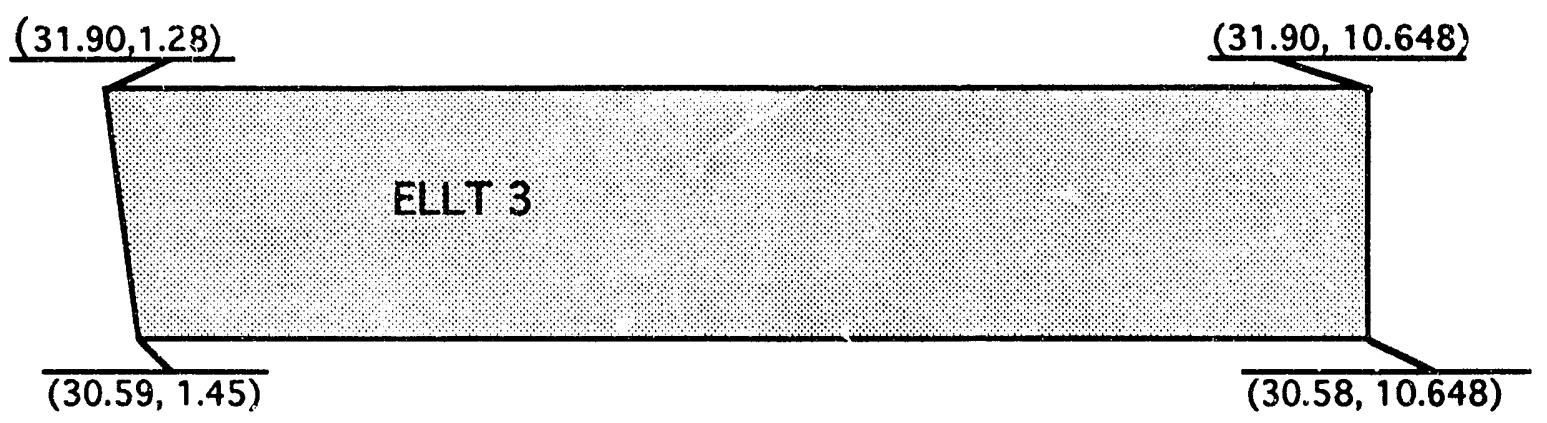

Figure 2. ELLT 2 and ELLT 3 Approximate Coordinates 


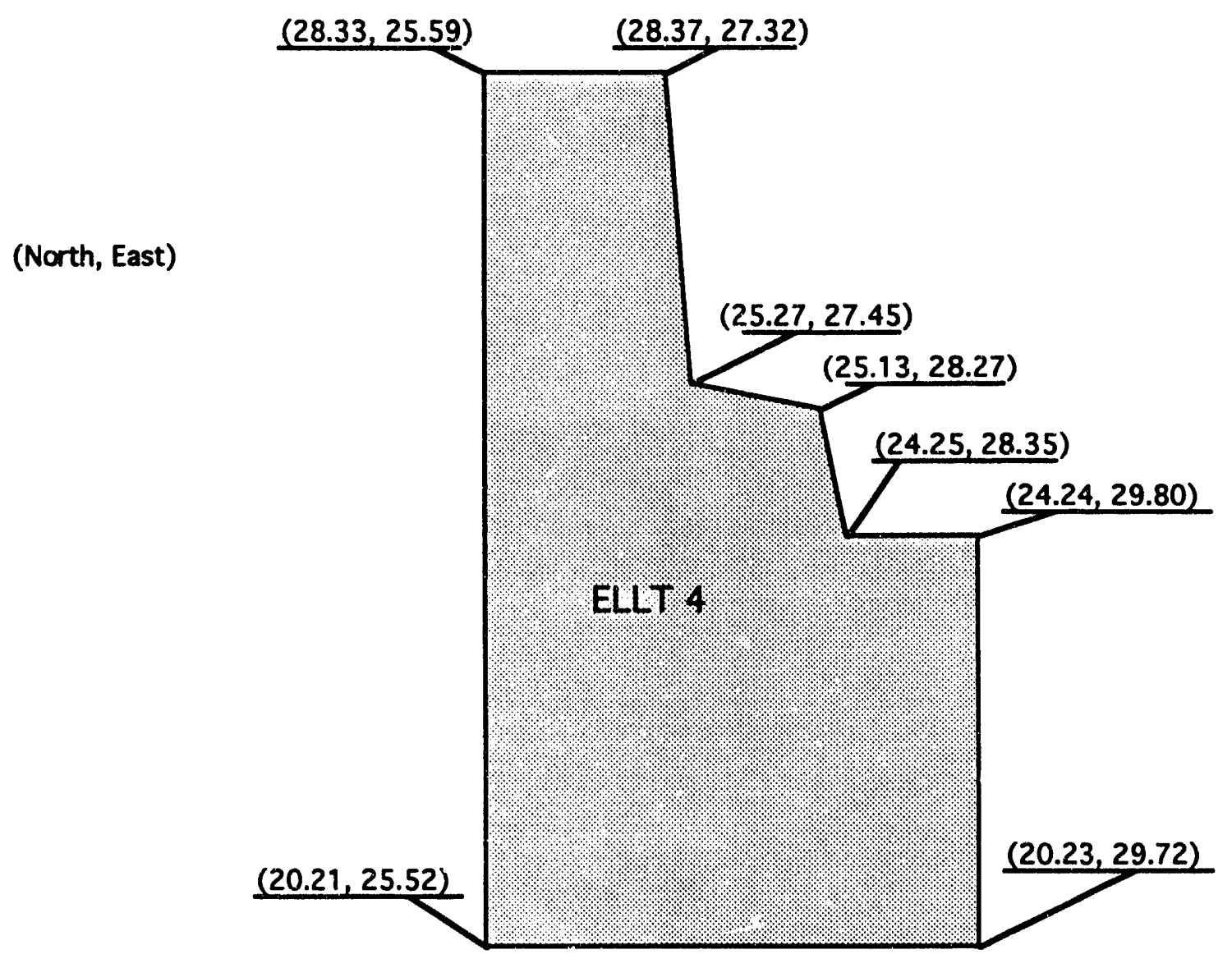

Trench Area 1

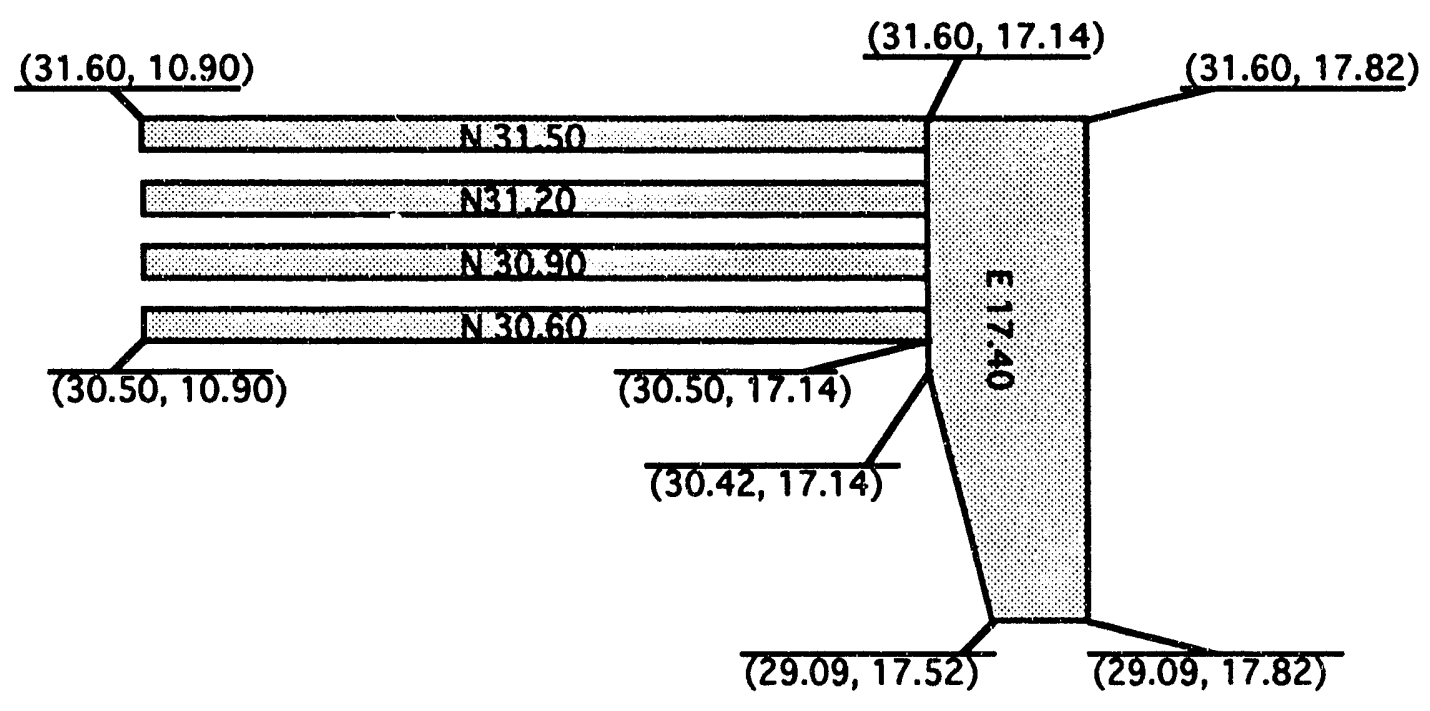

Figure 3. ELLT 4 and Trench Area 1 Approximate Coordinates 


\section{Trench Area 2}

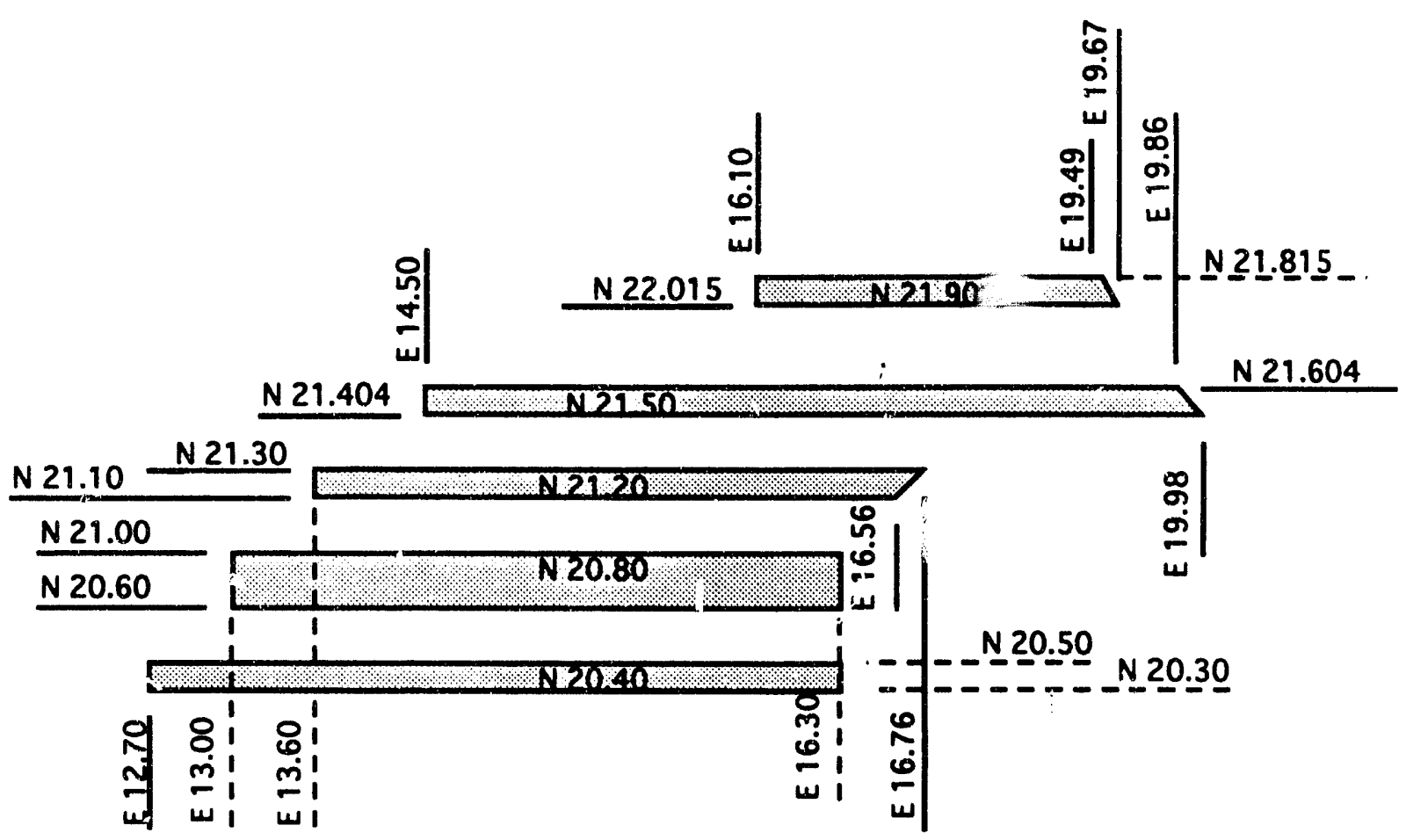

(North, East)

* Trench N21.90 appears on WMO drawings but does not appear in the COBRA database

Figure 4. Trench Area 2 Approximate Coordinates 


\section{Trench Area 3}

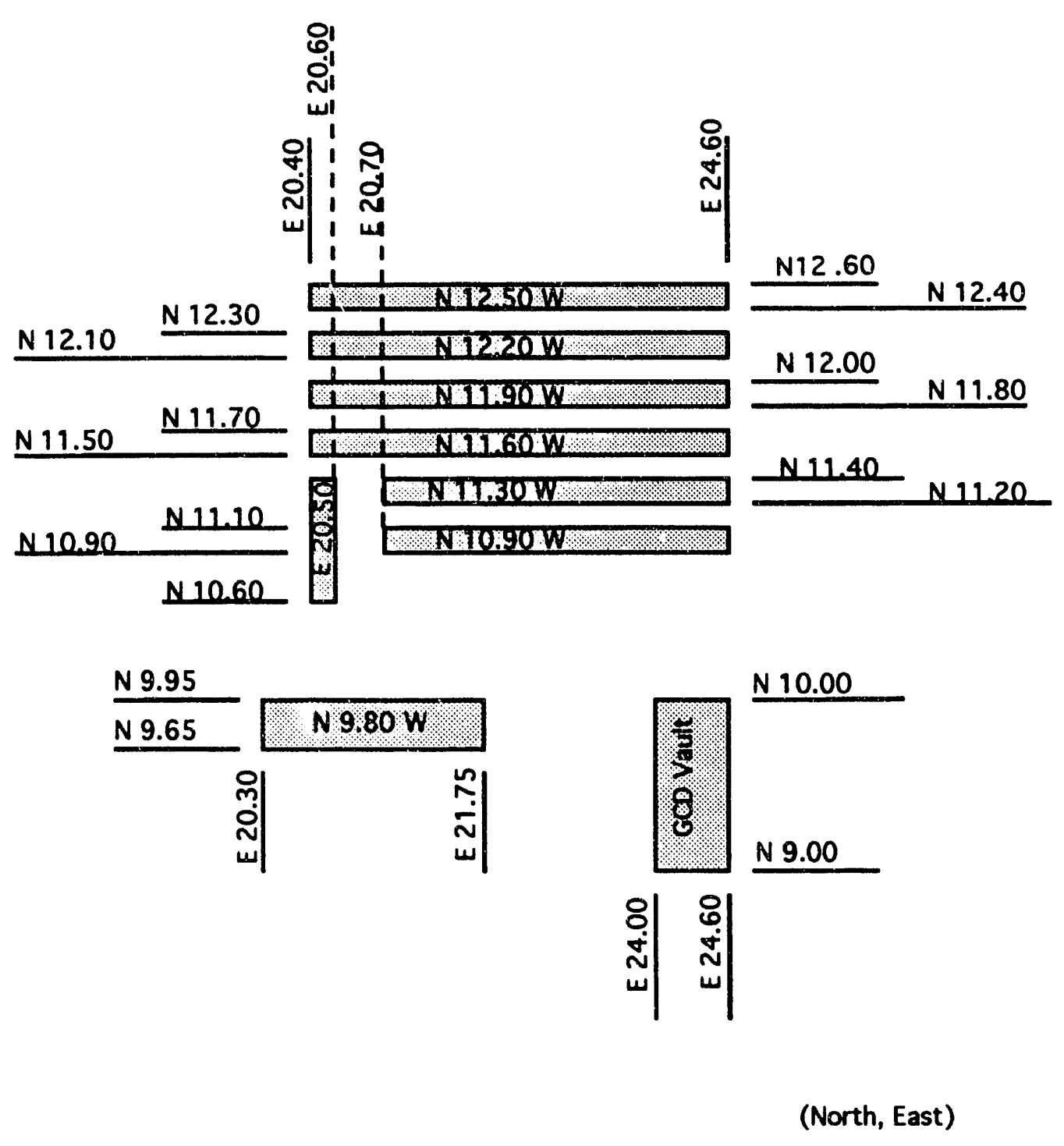

Figure 5. Trench Area 3 Approximate Coordinates 


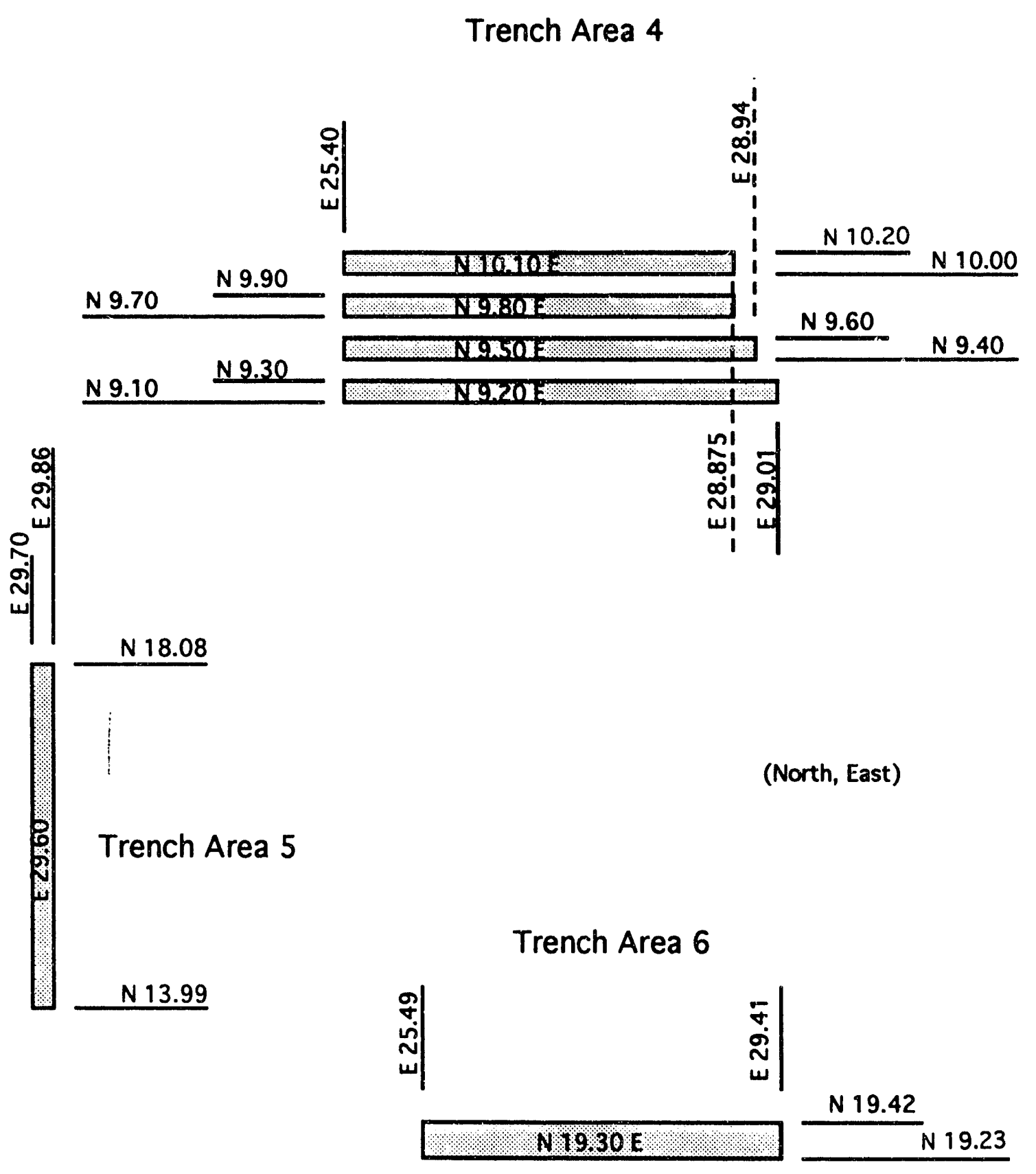

Figure 6. Trench Areas 4-6 Approximate Coordinates 


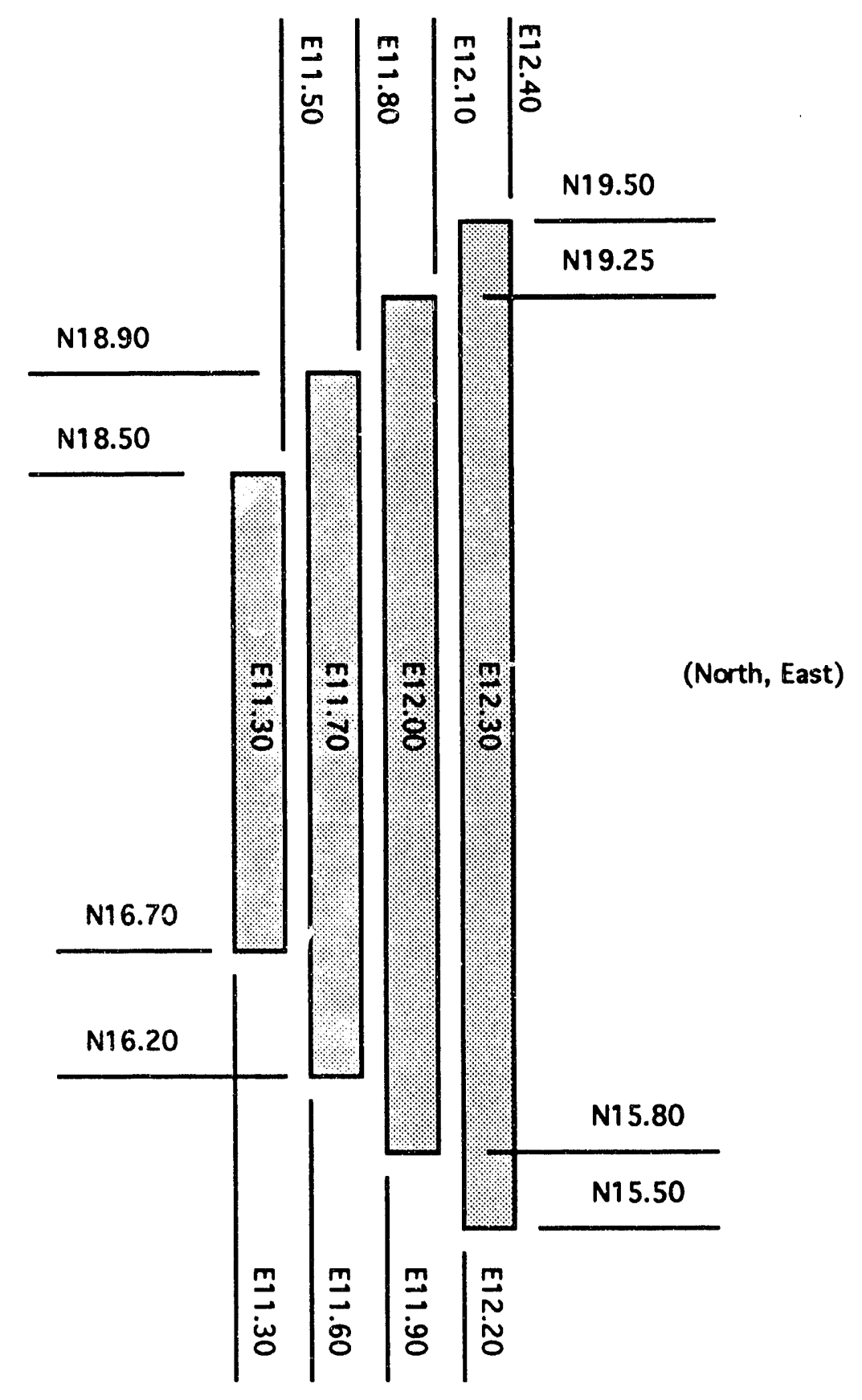

Figure 7. Additional Trenches; Approximate Coordinates 
coordinates are assigned by looking across the trench for stakes on the bank, a group of containers spread out over 20 or more feet may be given a single coordinate. A given coordinate can be interpreted to mean that position, plus or minus 15 feet.

No vertical location in the trench is recorded.

For a trench that runs East to West:

The North Coordinate assigned to all containers is the trench center line. This is also the "name" given to a slit trench;

The East Coordinate reflects the location of the container within the trench. The coordinate typically follows 5 foot increments. Since coordinates are assigned by looking across the trench for stakes on the bank, a group of containers spread out over 20 or more feet may be given a single coordinate. A given coordinate can be interpreted to mean that position, plus or minus 15 feet.

No vertical location in the trench is recorded.

Thus, the locations assigned are essentially only one-dimensional, corresponding to the approximate grid coordinates of the trench.

All containers in the EI.LTs were stacked in accordance with Burial Ground Procedure DPSOL 643-G-2037, Storage Solid Low-Level Radioactive Waste in Engineered Low-Level Trench. This procedure requires the matrix to be maintained in a stair-step design as shown in Figure 8. Shipments of EU containers are given special attention in accordance with DPSOL 643-G-2013-Q. The WMO supervisor assigns a location for each EU container based on previous EU container locations. The intent is to ensure that there is at least one "clean" box between EU boxes. Multiple EU boxes that arrive in the same shipment are separated across a row of an ELLT to ensure separation. EU boxes are not, however, checked against previous shipments to ensure that they are stacked properly.

The separation of EU boxes relies on the operator knowing which previously placed boxes contain EU because the assigned coordinates do not define their exact physical locations (i.e., X-Y-Z locations). Several factors combine to make it difficult for the operator to know if surrounding boxes contain EU:

1) EU boxes are not marked in any way;

2) the amount of time between the loading of two EU boxes may be days, weeks, or even months;

3) it is possible to have a large number of boxes loaded (across a row of the trench) between the time when EU boxes are stacked in the stair-step pattern; 

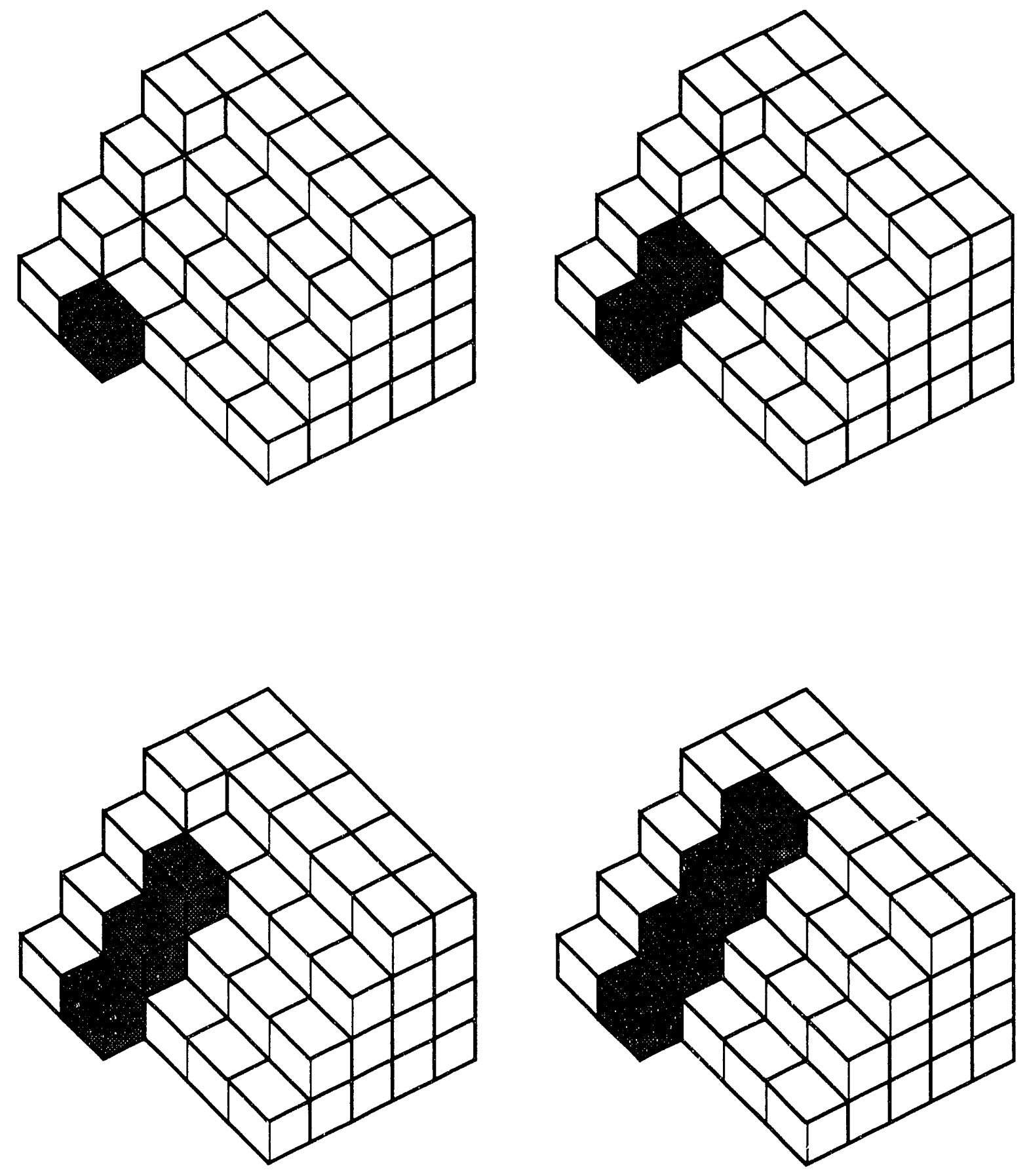

Figure 8. Stair-Step Loading Pattern 
4) a previous EU box may have been loaded by a different operator; and

5) the contents of surrounding boxes are not formally reviewed before a container with substantial EU is buried.

It cannot be proven that the EU boxes have been separated for the existing conditions. The possibility exists that EU boxes have been stacked on top of one another.

\section{LURWDF Burial Records}

Examination of specific locations in the COBRA database has revealed several discrepancies. Tables 2 through 4 show sample location data for ELLTs 2-4, respectively. In the uniform ELLTs, the number of containers varies widely from location to location. ELLT 2 varies from 3 to 1,499 boxes and from 0 to $1,075 \mathrm{~g}$ of EU per location. For ELLT 4, the total number of boxes per location varies from 1 to 1,771. The data for ELLT 3 show similar characteristics. Detailed investigation has revealed that the database reflects the loading patterns used.

Each ELLT was filled by rows across its entire width, starting at one end. When the ELLT was nearly filled, the orientation of the containers was changed to accommodate maneuvering of the box handling truck. This change in orientation, which complicated the task of assigning locations to containers, occurred at the north end of ELLT 2 and the east end of ELLT 3. ELLT 4 is still open, but a similar orientation change is expected. In ELLT 2, more than 3000 containers were assigned to three locations (N19.50 and N19.55, and N19.60) in the area of orientation change. ELLT 3 is similar; 1500 containers are listed in location E9.75. These areas were being filled at the time that significant amounts of $\mathrm{EU}$ were being received from Naval Fuels, so many of these containers contain more than $150 \mathrm{~g}$ of EU.

COBRA records also show that a number of containers with substantial EU were assigned locations that lie outside of the physical boundaries of the ELLTs. This may be due to an error in data entry, an error in assigning the coordinate, or an error in trench boundary coordinate definitions. For the purpose of these analyses, those containers are assumed to lie within the first seven rows of the trench matrix. Some containers are assigned a coordinate other than that of the trench center line, but within the boundaries of the trench. These are most likely the result of an error during data entry. A summary of the findings from COBRA evaluations for ELLTs is given in Appendix A.

EU boxes were buried in slit trenches according to the same procedure used for the ELLTs, and location coordinates are assigned in a similar manner. Separation of the EU boxes, however, is accomplished by backfilling with three feet of dirt after each EU burial. Boxes in the slits are not in a structured matrix and are prone to move during burial activities. The box 
Table 2. Sample COBRA data for ELLT 2

\begin{tabular}{cccc}
$\begin{array}{c}\text { Location } \\
\text { Coordinates }\end{array}$ & $\begin{array}{c}\text { No. of } \\
\text { Boxes }\end{array}$ & $\begin{array}{c}\text { Boxes with } \\
\text { U-235 }\end{array}$ & $\begin{array}{c}\text { grams of } \\
\text { U-235 }\end{array}$ \\
\hline N18.90 E13.77 & 3 & 3 & 18.2 \\
N18.95 E13.77 & 147 & 0 & 0 \\
N19.00 E13.77 & 579 & 29 & 47.7 \\
N19.05 E13.77 & 3 & 3 & 56.7 \\
N19.15 E13.77 & 99 & 0 & 0 \\
N19.20 E13.77 & 234 & 3 & 54.8 \\
N19.25 E13.77 & 51 & 10 & 480.5 \\
N19.30 E13.77 & 349 & 16 & 228.4 \\
N19.35 E13.77 & 199 & 13 & 546.7 \\
N19.40 E13.77 & 574 & 43 & 818.9 \\
N19.45 E13.77 & 47 & 17 & 399.2 \\
N19.50 E13.77 & 1499 & 56 & 1075.0 \\
N19.55 E13.77 & 1053 & 36 & 965.9 \\
N19.60 E13.77 & 630 & 27 & 722.6
\end{tabular}

Table 3. Sample COBRA data for ELLT 3

\begin{tabular}{cccc}
$\begin{array}{c}\text { Location } \\
\text { Coordinates }\end{array}$ & $\begin{array}{c}\text { No. of } \\
\text { Boxes }\end{array}$ & $\begin{array}{c}\text { Boxes with } \\
\text { U-235 }\end{array}$ & $\begin{array}{c}\text { grams of } \\
\text { U-235 }\end{array}$ \\
\hline N31.00 E02.20 & 3 & & \\
N31.00 E02.25 & 209 & 2 & 207.7 \\
N31.00 E02.30 & 3 & 2 & 669.6 \\
N31.00 E02.35 & 3 & 2 & 225.4 \\
N31.00 E02.50 & 221 & 6 & 244.6 \\
N31.00 E02.55 & 4 & 4 & 481.7 \\
N31.00 E02.65 & 309 & 9 & 422.1 \\
N31.00 E02.80 & 117 & 0 & 0 \\
N31.00 E02.90 & 41 & 8 & 210.4 \\
N31.00 E03.00 & 262 & 7 & 774.7
\end{tabular}


Table 4. Sample COBRA data for ELLT 4

\begin{tabular}{cccc}
$\begin{array}{c}\text { Location } \\
\text { Coordinates }\end{array}$ & $\begin{array}{c}\text { No. of } \\
\text { Boxes }\end{array}$ & $\begin{array}{c}\text { Boxes with } \\
\text { U-235 }\end{array}$ & $\begin{array}{c}\text { grams of } \\
\text { U-235 }\end{array}$ \\
\hline N22.43 E25.60 & 1 & 0 & 0 \\
N22.50 E26.40 & 135 & 0 & 0 \\
N22.65 E26.40 & 284 & 0 & 0 \\
N22.80 E26.00 & 1 & 0 & 0 \\
N22.80 E26.40 & 1692 & 5 & 45.8 \\
N23.00 E26.40 & 1771 & 8 & 80.1 \\
N23.00 E29.70 & 1 & 0 & 0 \\
N23.00 E29.80 & 1127 & 3 & 53.7 \\
N23.00 E29.85 & 1 & 1 & 0.9 \\
N23.00 E29.90 & 1 & 1 & 15.0 \\
N23.25 E26. & 368 & 2 & 22.6
\end{tabular}

locations, therefore, are assumed to be even less accurate than for the ELLTs, and separation by three feet of dirt is not measured or guaranteed.

The estimated number of boxes for each ELLT and slit trench as given in the COBRA database is shown in Table 5. The data show that the largest amount of EU is in ELLT 3 and the least in ELLT 4. Several of the slit trenches contain significant quantities of EU. From detailed examination of the burial records, it appears that the total number of EU containers within a trench is correct, and it is assumed that the mass of EU within individual containers is correct.

\subsection{Physics Calculations}

Previous analysis of criticality of B-25 boxes (Reference 2) concluded that a maximum of $150 \mathrm{~g}$ of U-235 per container would be safe in an infinite array under all conditions. Calculations were performed for boxes containing $150,175,200,250$, and $300 \mathrm{~g}$ of EU. The EU in each box was modeled as a sphere in the corner of the container, and the remainder of the box was assumed to be filled with polyethylene (i.e., a good moderator). The box was assumed to be intact. For boxes containing over $150 \mathrm{~g}$ of EU, it was concluded that administrative controls for separation of EU boxes must be maintained to ensure that a criticality does not occur.

Scoping analyses have been performed as part of this USQE (Reference 3) to determine the mass of EU required for a critical configuration, given that EU boxes were placed next to one another. The basic assumption was that EU in adjacent containers created an optimally moderated sphere with either a water or dirt reflector. The containers themselves were not modeled 
Table 5. Summary Of U-235 Containers

In Each Trench

\begin{tabular}{|c|c|c|c|c|c|c|c|}
\hline \multirow{2}{*}{ Trench } & "Boxes" & & $100-$ & $150-$ & $200-$ & & Total \\
& with no & $<100 \mathrm{~g}$ & $150 \mathrm{~g}$ & $200 \mathrm{~g}$ & $250 \mathrm{~g}$ & $>250 \mathrm{~g}$ & grams \\
& $\mathrm{U}-235$ & $\mathrm{U}-235$ & $\mathrm{U}-235$ & $\mathrm{U}-235$ & $\mathrm{U}-235$ & $\mathrm{U}-235$ & $\mathrm{U}-235$ \\
\hline
\end{tabular}

Trench Area 1

\begin{tabular}{|c|c|c|c|c|c|c|c|}
\hline E17.40 & 444 & 61 & 1 & & 22 & 7 & 8,896 \\
\hline N30.60 & 397 & 6 & & & & & 3 \\
\hline N30.90 & 334 & 26 & & & & & 286 \\
\hline N3 31.20 & 363 & 111 & 2 & 2 & & 6 & 4,344 \\
\hline N31.50 & 517 & 93 & 7 & 1 & 12 & 25 & 12,853 \\
\hline
\end{tabular}

Trench Area 2

\begin{tabular}{|c|c|c|c|c|c|c|c|}
\hline N20.40 & 93 & & & & & & 0 \\
\hline N21.20 & 387 & 15 & 2 & & & & 438 \\
\hline N21.50 & 732 & 112 & 2 & 8 & 14 & & 8,416 \\
\hline N20.80 & 193 & & & & & & 0 \\
\hline
\end{tabular}

Trench Area 3

\begin{tabular}{|c|c|c|c|c|c|c|c|}
\hline GCD & 176 & 2 & & & & & 16 \\
\hline N09.80W & 74 & & & 1 & & & 188 \\
\hline N10.90W* & 210 & 25 & & & & & 367 \\
\hline N11.30W & 171 & 5 & & & & & 163 \\
\hline N11.60W & 151 & 9 & & & & & $<1$ \\
\hline N11.90W & 218 & 14 & 2 & 2 & 2 & 4 & 2,508 \\
\hline N12.20W & 190 & 1 & & & & & $<1$ \\
\hline N12.50W & 250 & & & & & & 0 \\
\hline E20.50 & 41 & & & & & & 0 \\
\hline
\end{tabular}

Trench Area 4

\begin{tabular}{|c|c|c|c|c|c|c|c|}
\hline N09.20E & 182 & 61 & 3 & & & & 1,106 \\
\hline N09.50E & 320 & 33 & & & 1 & & 422 \\
\hline N09.80E & 196 & 32 & & & & 2 & 828 \\
\hline N10.10E & 159 & 11 & & & & & 2 \\
\hline
\end{tabular}

Trench Area 5

\begin{tabular}{|l|l|l|l|l|l|l|l|}
\hline $\mathrm{E} 29.60$ & 383 & 67 & 5 & 6 & 23 & & 8,535 \\
\hline
\end{tabular}


Table 5, continued

\begin{tabular}{|c|c|c|c|c|c|c|c|}
\hline \multirow{3}{*}{ Trench } & "Boxes" & & $100-$ & $150-$ & $200-$ & & Total \\
& with no & $<100 \mathrm{~g}$ & $150 \mathrm{~g}$ & $200 \mathrm{~g}$ & $250 \mathrm{~g}$ & $>250 \mathrm{~g}$ & grams \\
& $\mathrm{U}-235$ & $\mathrm{U}-235$ & $\mathrm{U}-235$ & $\mathrm{U}-235$ & $\mathrm{U}-235$ & $\mathrm{U}-235$ & $\mathrm{U}-235$ \\
\hline
\end{tabular}

Trench Area 6

\begin{tabular}{|l|l|l|l|l|l|l|l|}
\hline N19.30 & 330 & 35 & 1 & 4 & 11 & & 4,362 \\
\hline
\end{tabular}

Other Trenches

\begin{tabular}{|l|l|l|l|l|l|l|l|}
\hline E11.30 & 101 & & & & & & 0 \\
\hline E11.70 & 203 & & & & & & 0 \\
\hline E12.00 & 361 & & & & & & 0 \\
\hline E12.30 & 277 & & & & & & 0 \\
\hline
\end{tabular}

Engineered Low Level Trenches (ELLTs)

\begin{tabular}{|l|c|c|c|c|c|c|c|}
\hline ELLT 2 & 14,060 & 582 & 22 & 16 & 8 & 3 & 14,749 \\
\hline ELLT 3 & 13,392 & 422 & 82 & 32 & 41 & 18 & 45,986 \\
\hline ELLT 4 & 19,003 & 278 & 7 & 7 & 5 & & 8,410 \\
\hline
\end{tabular}

* As of May 1, 1992

(i.e., it was assumed that no credit could be taken for absorption by the container materials), and box contents which could serve as neutron poisons were not included. A sandy soil cover above and below the configuration was modeled, and mirror boundary conditions were applied to the side faces (creating a unit cell). It was assumed that DC resulted in an accordion-like collapse of the boxes and that the EU did not move out of the boxes. Vertical spacing of adjacent EU spheres was varied to simulate dynamic compaction. The HRXN-KENO members of J70 KOKO (Reference 4) were used for eigenvalue calculations. The input model is shown in Figure 9.

The calculated critical masses for the optimal geometry were $630 \mathrm{~g}$ for a water reflected sphere, and $550 \mathrm{~g}$ for a dirt (sandy soil) reflected sphere. The eigenvalue calculations suggest that no neutron interaction is expected between U-235 spheres. A center-to-center spacing between spheres (dimension D1 on Figure 9) of less than $40 \mathrm{~cm}$ is required before evidence of neutron interaction is seen. Spacing of that order corresponds to DC of approximately $15 \mathrm{ft}$. If compacted, it is expected that the ELLTs would only be compacted $6 \mathrm{ft}$. This suggests that DC will not increase the likelihood of criticality for base configurations where the spheres contain less than the 


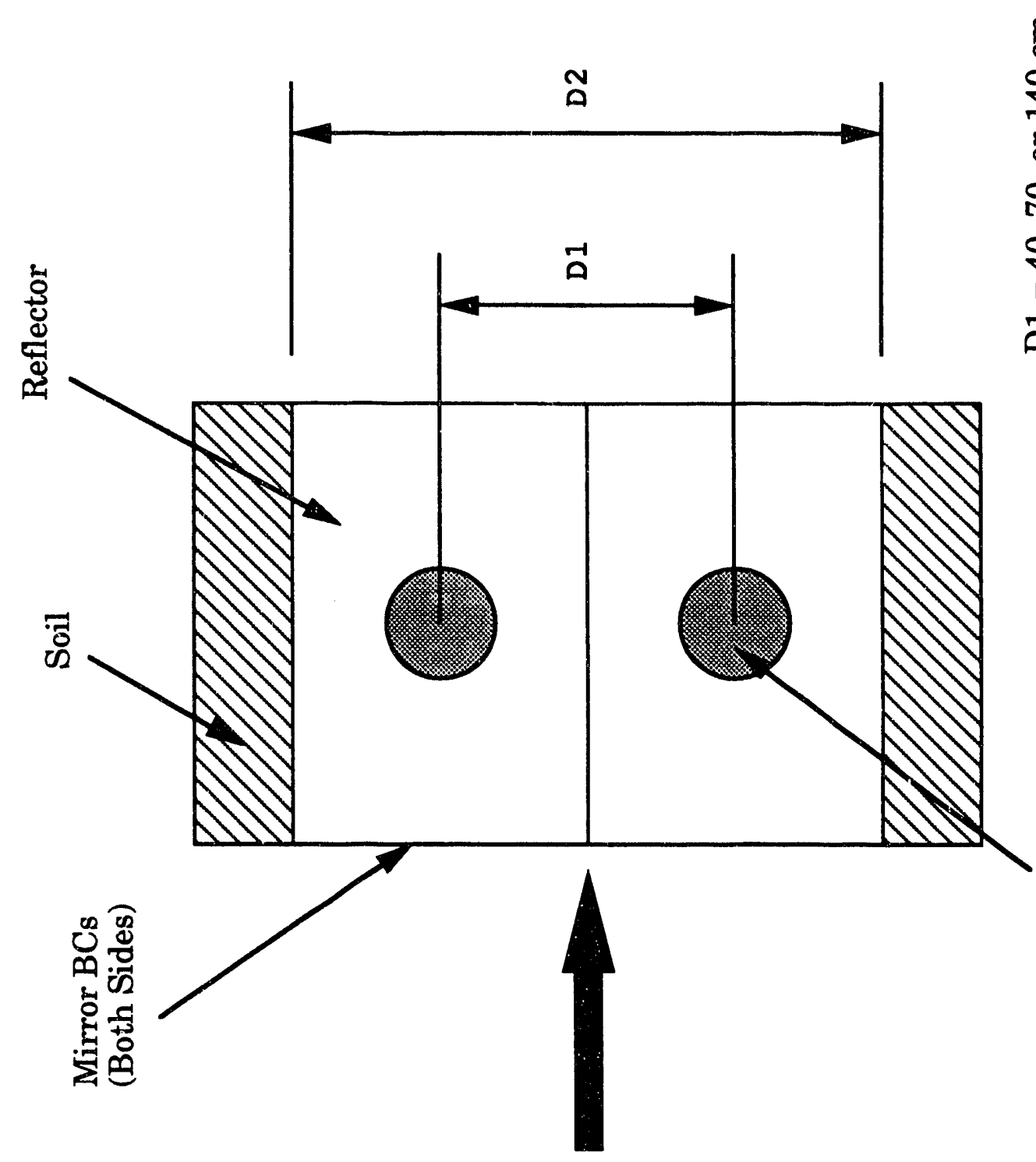

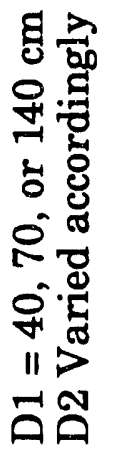

I

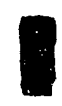

I

I

1

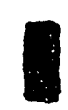

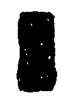

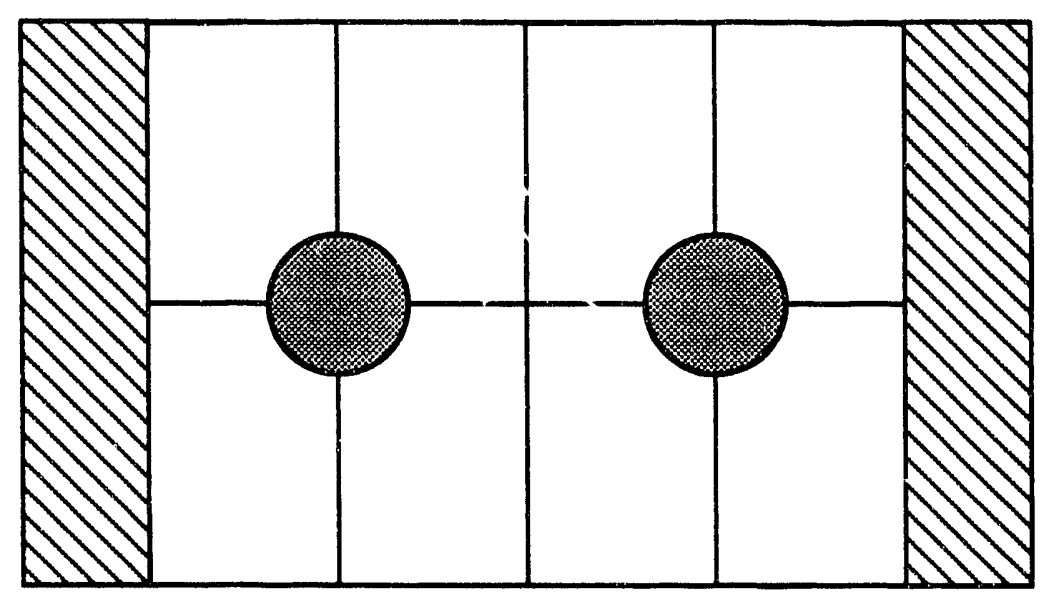

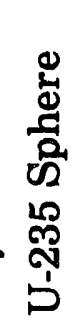

范 
critical mass. The analyses also demonstrated that $\mathbf{k}$-eff is not sensitive to the thickness of the overlying cover.

Review of the previous criticality studies (Reference 2) revealed that a $175 \mathrm{~g}$ sphere of U-235 per container was safe in an infinite array under all conditions except for one specific case containing a high volume of polyethylene reflector. The calculated eigenvalue with applied safety margins for this one case was less than the critical eigenvalue but slightly greater than the "safe" eigenvalue. This suggests that combinations of four boxes each containing $175 \mathrm{~g}$ (or a total of $700 \mathrm{~g}$ ) would be subcritical. Additionally, the 200-Area Criticality Audit Committee (CAC) identified two references that list $820 \mathrm{~g}$ as the calculated or observed critical mass of U-235 solution spheres at optimum moderation (Reference 5). The subsequent statistical analysis combining the data assessment with physics calculations was performed assuming critical mass values of $630 \mathrm{~g}, 700 \mathrm{~g}$, and $820 \mathrm{~g}$. Note that the assumption that the EU forms an optimally moderated sphere is a conservative assumption that is used in criticality assessments. However, using $820 \mathrm{~g}$ for the statistical analysis assumes no safety margin for potential errors in EU content listed in COBRA.

\subsection{Statistical Assessment}

A statistical approach was used to determine the possible combinations of boxes within each ELLT matrix that could contain sufficient EU to form a critical mass. Possible combinations were limited to a three or four box pattern. It is not possible for a two box pattern to be critical in any of the trenches. The actual locations of the boxes were assumed to be within three rows ( \pm 15 feet) of the database coordinates because of the questions about the database, and it was assumed that boxes were loaded randomly within these 30 feet. Thus, all combinations of boxes resulting in EU boxes being chosen together were computed.

In addition to the container coordinates, the COBRA database contains the date that each box was received and the amount of $E U$ each one contained. It was assumed that the date and amount of EU were correct. Only B-25 boxes containing EU were considered; no 55 -gallon drums were included. It was assumed that the drums were stored around the edges of the ELLTs in a pattern that could not result in a criticality.

It was assumed that boxes containing greater than $115 \mathrm{~g}$ of EU received on the same day are separated by clean boxes (i.e., that the procedure was followed). All EU boxes are isolated within an individual row by placing clean boxes on either side. In addition, a clean box will be stacked on the diagonal of the stair step if received on the same day.

A SAS computer code was developed to calculate the box combinations. To ensure that each combination was counted only once, the code checked to make sure that at least one box in each combination had coordinates that 
Table 6. Probability of Assembling EU Containers

\begin{tabular}{|lccc|}
\hline & 630 grams & 700 grams & 820 grams \\
ELLT 2 & $8.5 \mathrm{E}-03$ & $1.9 \mathrm{E}-03$ & 0 \\
ELLT 2 & $1.3 \mathrm{E}-03$ & $3.7 \mathrm{E}-04$ & 0 \\
ELLT 3 & $3.9 \mathrm{E}-02$ & $8.1 \mathrm{E}-03$ & $1.3 \mathrm{E}-03$ \\
ELLT 4 & $6.7 \mathrm{E}-04$ & 0 & 0 \\
\hline
\end{tabular}

* Separating 1988-89 boxes from those loaded in 1987 (Section 2.6.2)

had not previously been considered. Then it checked the date received to ensure that it was different than the other boxes in the combination.

The probabilities of assembling combinations of boxes containing a potentially critical mass a:e given in Table 6 for each of the ELLTs. The calculated probabilities for $630 \mathrm{~g}$ are significantly above 1.0E-06 for all of the ELLTs. As expected, the calculated probabilities decrease as the mass of EU considered increases. For $700 \mathrm{~g}$, the probability for ELLT 4 is zero, but the probabilities for ELLTs 2 and 3 are still greater than 1.0E-06. For $820 \mathrm{~g}$, the probability for ELLT 2 is also zero, but ELLT 3 is 1.3E-03. As shown in Table 5, ELLT 3 contains a large amount of EU and a considerable number of boxes with greater than $\mathbf{1 5 0} \mathrm{g}$ per box, so the probabilities are expected to be high.

A statistical assessment was not completed for the slit trenches because of the random nature of the burials (i.e., a matrix of boxes does not exist). Slit trenches were assumed to be safe (from a criticality standpoint) if one of two conditions exists: 1) the entire trench contains less than $700 \mathrm{~g} \mathrm{EU}$, or 2) the containers with greater than $115 \mathrm{~g}$ of EU were widely separated (e.g., $40 \mathrm{ft}$.). This takes into account the uncertainty in container locations, data records, and separation of the containers during burial.

\section{Special Considerations}

Several important factors from the LLRWDF operation were included as part of this analysis. These are discused herein.

\subsubsection{Solubility of EU}

Previous analysis of the enriched uranium waste from Naval Fuels (Reference 6) revealed that it is soluble and could be recovered with leachates ranging from water to $0.1 \mathrm{M}$ nitric acid. When compacted, the burial containers (e.g., B-25s) will be breached, exposing the EU waste to potential water in the trench. The mixture would most likely be released to the environment through seepage into the ground water. Thus, DC will cause introduction of EU to ground water sooner than degradation of the 
containers under natural conditions. The cap, however, will minimize water ingression to the trenches and delay the release of EU.

\subsubsection{ELLT 2 Exclusions}

ELLT 2 was filled primarily before 1987. B jxes with north coordinates less than N19.20 received in 1988-89 in ELLT 2 are assumed to be placed along the edges. WMO was loading a large number of EU boxes into ELLT 3 at the time and made a deliberate attempt to separate boxes with large amounts of EU by placing them around the edge of ELLT 2. Probabilities of assembling EU boxes for ELLT 2 were calculated both by including these high content boxes and by excluding them on the assumption they were isolated by WMO. The probabilities are included in Table 6.

\subsubsection{Flooding of ELLT 4}

On August 22, 1990, the burial ground experienced large amounts of rainfall. As a result, ELLT 4 was flooded and approx :mately 500-700 boxes were displaced from their burial location (Reference 7). It was assumed that boxes stacked before the flood in locations sufficiently removed from the area being loaded at the time of the flood were not displaced. During the cleanup of the flood, the displaced boxes were replaced randomly (i.e., no attempt was made to place them in their original locations). This is not significant since the EU contents in each of these containers was low, and criticality would be impossible, even under ideal moderation and geometry. In addition, water was monitored as it was pumped from the ELLT, and no evidence of criticality was observed.

ELLT 4 is presently about $90 \%$ full. The southern most end of the trench remains open and receives shipments of B-25s regularly. There have been no recent shipments of EU placed in ELLT 4, and conversations with FR and WMO personnel indicate that EU boxes are currently placed on TRU pads rather than in the ELLT. No additional EU is expected to be added to the ELLT. The sump at the southern end of the ELLT, however, is still being pumped. Given the fact that many of the boxes in the ELLT contain water as a result of the flood, and the EU is in a soluble form, it is recommended the sump continue to be pumped and monitored during ELLT operations. DC will breach the boxes and result in water (and potentially dissolved EU) being released. To prevent potential criticality in the sump, it is recommended that the sump be back filled with dirt prior to ELLT closure. Criticality of the sump was not evaluated explicitly as part of this effort, but eliminating the volume where water can collect will minimize the possibility of a criticality.

\subsubsection{Test Results}

Preliminary results of recent DC tests (Reference 8) suggest that buried containers may burst and release their contents during DC. Review of the test results suggest a sudden vincontrolled expulsion of compressed air 
from B-25 boxes with a high void ratio. As the boxes are compacted, the air pressure increases until the box fails, ejecting both the compressed air and waste materials. When the releases vented through the ground, soil was observed to be projected 100 feet laterally through the air. Vents appeared up to $\mathbf{1 0}$ feet away from the point of impact, and fissures matching the interfaces of the boxes displayed some "pumping" of air up to 20 feet away from the point of impact. Additional testing of boxes clearly demonstrated that a high pressure release of compressed air was taking place and waste was being ejected from the boxes. These "events" were not confined to the initial drop of the weight, but did occur after sequential drops in the same location.

Collapse of the boxes, therefore, is not predicted to be accordion-like, and there is a strong possibility that waste will be ejected from the boxes during compaction. If the EU moves laterally during $\mathrm{DC}$, the probabilities of assembling a critical mass would have to be recomputed for the predicted configuration. A new configuration would be difficult (if not impossible) to predict, so the uncertainties would be large. Thus, the possibility of assembling a critical mass of EU cannot be eliminated. In addition, there is a possibility of generating airborne contamination resulting in increased risk to the workers during DC.

\subsection{CONCLUSIONS}

The possibility of criticality in the LLRWDF trenches cannot be precluded: there is a large amount of $\mathrm{EU}$ present in the trenches; significant uncertainties in the EU locations exist; and movement of the EU during DC cannot be predicted. As a result, the risk to workers during dynamic compaction could be significant. It is recommend that portions of ELLT 2 north of coordinate N19.45 and all of ELLT 3 not be compacted. In addition, it is recommended that seven slit trenches not be compacted: E17.40, N31.20, N31.50, N21.50, N11.90W, E29.60, and N19.30. The basis for these conclusions is that $700 \mathrm{~g}$ can potentially be assembled to form a critical mass. If $820 \mathrm{~g}$ is used as a screening criteria, then ELLT 2 and trench N19.30 can be assumed to be clear and can be compacted. As was discussed earlier, no safety margin is included if $820 \mathrm{~g}$ is used.

\subsection{SUMMARY}

During the operation of the LLRWDF, large amounts (greater than $100 \mathrm{~kg}$ ) of enriched uranium (EU) were buried. This EU came primarily from the closing and decontamination of the Naval Fuels Facility in the time period from 1987-89. Waste Management Operations (WMO) procedures were used to keep the EU boxes separated to prevent possible criticality during normal operation. Dynamic compaction will crush the containers in the LLRWDF and result in changes in their geometry.

Research of the LLRWDF operations and record keeping practices have shown that the EU contents of trenches are known, but details of the 
arrangement of the contents cannot be proven. Reviews of the trench contents combined with analysis of potential critical configurations, revealed that some portions of the LLRWDF can be expected to be free of criticality concerns while other sections have credible probabilities for the assembly of a critical mass, even in the uncompacted configuration.

Preliminary results of recent DC tests suggest that buried containers may burst and release their contents during DC. If the EU moves laterally during DC, the probabilities of assembling a critical mass would have to be recomputed for the predicted configuration. A new configuration would be difficult (if not impossible) to predict. Thus, the possibility of assembling a critical mass of EU cannot be eliminated. In addition, there is a possibility of generating airborne contamination resulting in increased risk to the workers during DC.

It is recommended, therefore, that portions of ELLT 2 north of coordinate N19.45 and all of ELLT 3 not be compacted. In addition, it is recommended that seven slit trenches not be compacted: E17.40, N31.20, N31.50, N21.50, N11.90W, E29.60, and N19.30. It is also suggested that the WMO procedure for handling EU boxes be reviewed for adequacy. Finally, it is recommended that the sump at the southern end of ELLT 4 continue to be pumped and monitored during ELLT operation and filled prior to ELLT closure.

\subsection{RENERRENCES}

1. S. J. Hurrell, et.al., Safety Analysis - 200 Area, Savannah River Plant Burial Ground Operations, DPSTA-200-10, Supp-8, E.I. DuPont de Nemours \& Co., October 1988.

2. J. A. Schlesser, Nuclear Criticality Safety Analysis 87-15, Burial of Enriched Uranium In B-25 Boxes, Inter-Office Memorandum DPSPU-87-272-145, October 1, 1987.

3. J. F. Mincey, ELLT Criticality Safety Scoping Studies For B-25's (U), SRT-CMA-920046, May 18, 1992.

4. H. K. Clark, User's Manual: JOSHUA Nuclear Criticality Safety Modules, DPSTM-86-700-3, March 1987.

5. H. P. Holcomb, References For Use Of $820 \mathrm{~g}$ Enriched Uranium As Critical Mass For LLRWDF USQE (U), Inter-Office Memorandum WER-ERG-920775, August 12, 1992.

6. H. P. Holcomb, Recovery Of Enriched Uranium From Naval Fuels Waste By Leaching, Inter-Office Memorandum DPSPU-87-272-176, December 3, 1987.

7. Type B Investigation Report, Flooding of the 643-7G Burial Ground At The Savannah River Site On August 22, 1990 (U), SWDF-90-001, October 15, 1990.

8. S. R. McMullin, Interim Report: Dynamic Compaction Analysis of Kaolin Clay LLRWDF Assessment and Closure (U), Inter-Office Memorandum WER-ERG-920926, September 30, 1992. 


\section{APPENDIX A}

Evaluation of COBRA Records for ELLTs 2-4 


\section{A.1 Evaluation of COBRA Records for ELLTs $2-4$}

Due to the questions about the available data and some simplifications made for the location of containers buried in LLRWDF, certain areas are assumed to be laid out differently than documentation shows. The following is a list of assumptions made as part of this study.

- The centerline of each trench is recorded as one of the coordinates for every container in that trench. Therefore, the only value of this information is to identify in which trench a container lies.

- The coordinate assigned to each container that measures position along the length of a trench is an approximation. There is a good chance that a given container is within \pm 3 locations of its recorded location.

- Since there is no record of a vertical coordinate, containers are just as likely to be in any of the four tiers of an ELLT, or at any height within a slit trench.

- Containers in ELLT 2 recorded in COBRA as being South of N15.20 (Section I of Figure A-1, A:) were all buried outside of the general trench matrix (i.e., along the banks of the trench). It is assumed they do not break the pattern of loading (i.e., the matrix).

- Containers that were placed in ELLT 2, between coordinates N17.45 and $\mathrm{N} 19.50$, and prior to 1-1-88 (Section II of Figure A-1, A:), are assumed to be in a separate matrix from those buried in the same coordinates after 1-1-88 (Section III of Figure A-1).

- The final 1300 containers buried in ELLT 2 are in North to South rows at the North end of the trench (Section IV of Figure A-1, A:). Most are recorded in coordinate $\mathrm{N} 19.50$ or $\mathrm{N} 19.55$.

- Waste in ELLT 3, recorded as E1.50 to E2.35 (Section I of Figure A-1, B:) is buried west of the trench, outside of the B-25 matrix.

- Containers in ELLT 3 with coordinates of E9.70 to E10.45 (Sections III and IV of Figure A-1, B:) are all within the area of E9.70 to E10.70 (i.e., boxes were loaded all the way to the end of the trench). There is no guarantee that containers with distinctly different coordinates are in separate locations. Since the COBRA records in these areas are inconsistent, the coordinates of these containers are all assumed to be E9.75, and probabilities for combinations of all EU boxes are calculated. For example, a container listed as E10.20 is just as likely to be next to one recorded as E9.75 as it is to be next to E10.10.

- The final 400 boxes loaded into ELLT 3 are in North to South rows at the Southeast corner of the trench, from E9.75 to E10.70 (Section IV of Figure A-1, B:). 


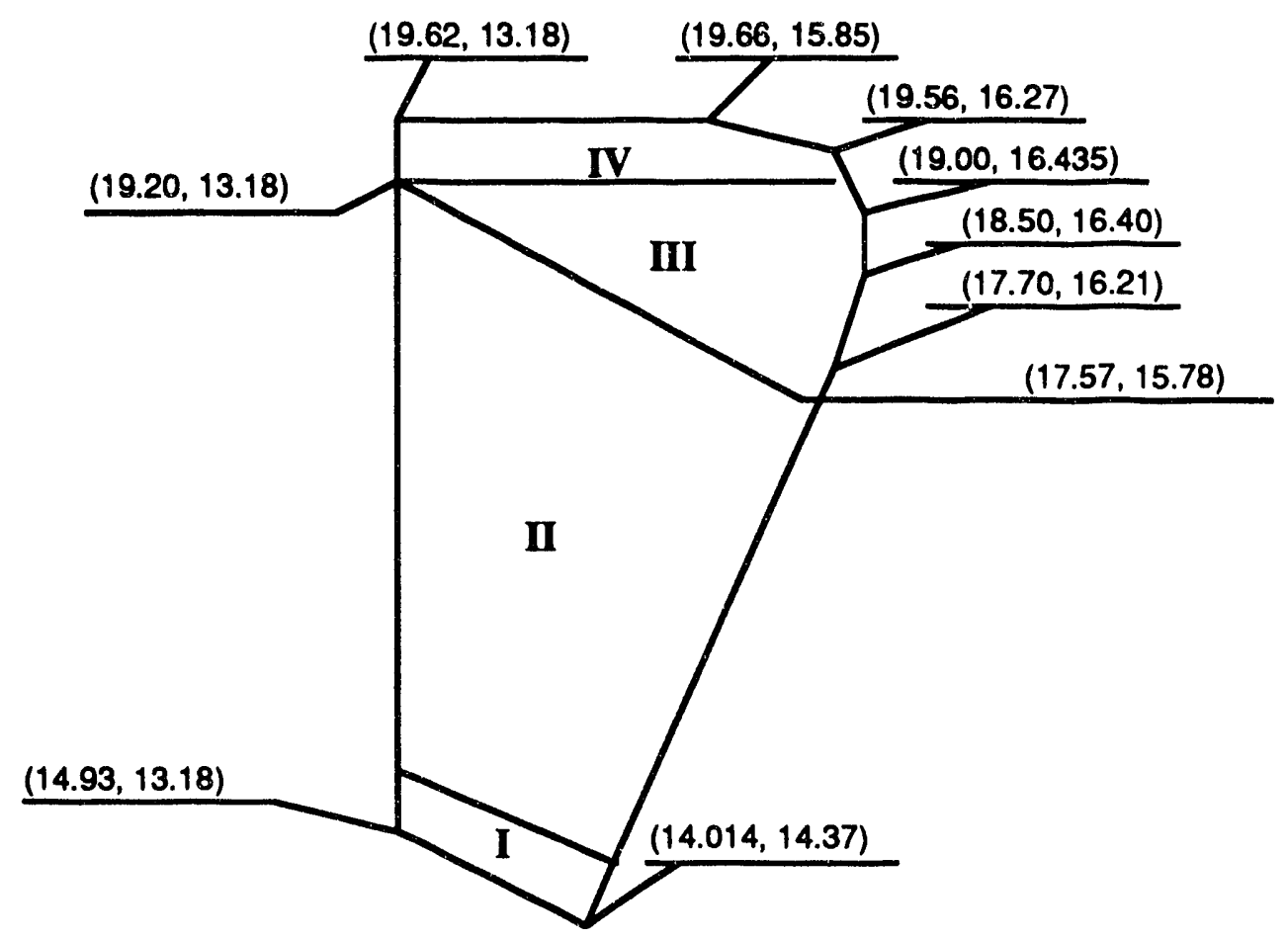

A: ELLT 2

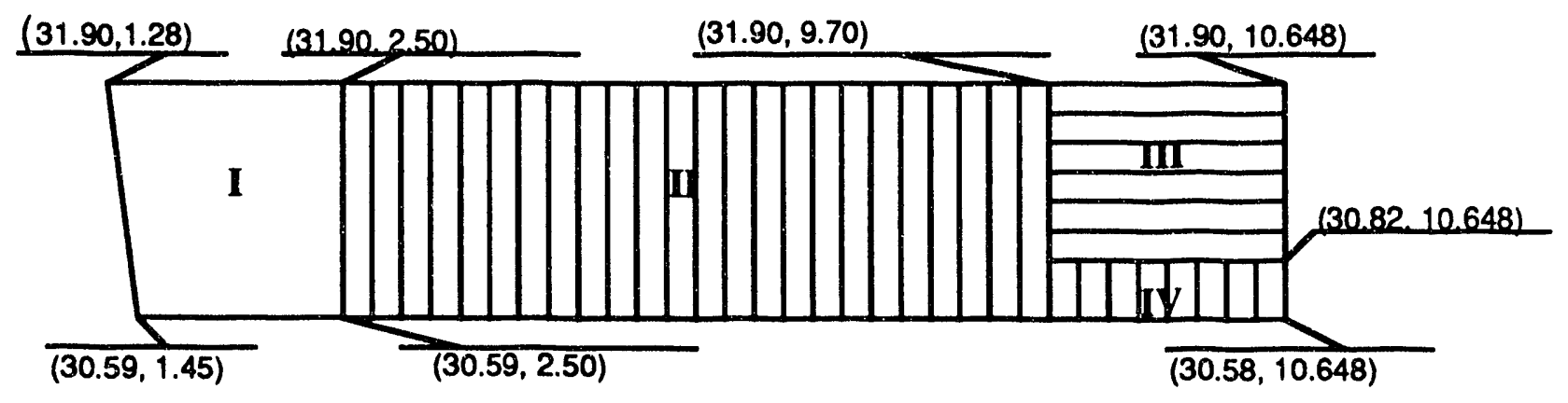

B: ELLT 3

Figure A-1. Loading Pattern for ELLTs 2 and 3 


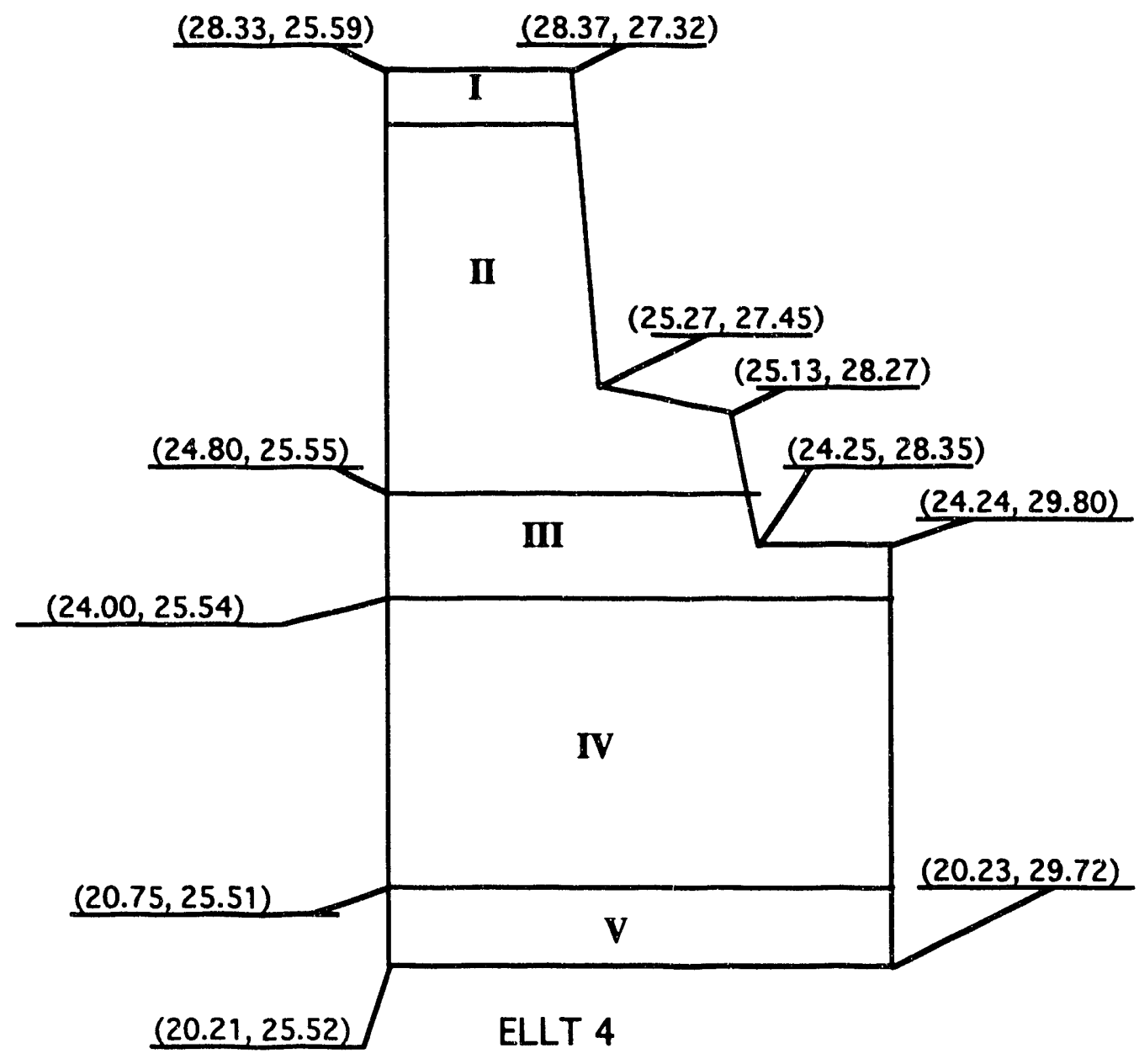

Figure A-2. Loading Pattern for ELLT 4 
- It is assumed that ontainers in ELLT 4 recorded as N28.35 to N28.60 (i.e., outside the trench boundary) are actually within the first seven locations of the matrix of containers recorded (Section I of Figure A-2).

- Containers in ELLT 4 North of N24.75 (Sections I and II of Figure A-2) maintained position through the flood of August 22, 1990.

- Containers in ELLT 4 South of N24.75 (Section 3 of Figure A-2), buried before 8-22-90, (recorded as N24.00 to N24.75) were all displaced by the flood and were replaced, in random order, from N24.00 to N25.00.

- Containers in ELLT 4 South of N24.00, buried after 8-22-90 (Sections IV and V of Figure A-2) were buried after the flood of 1990. 

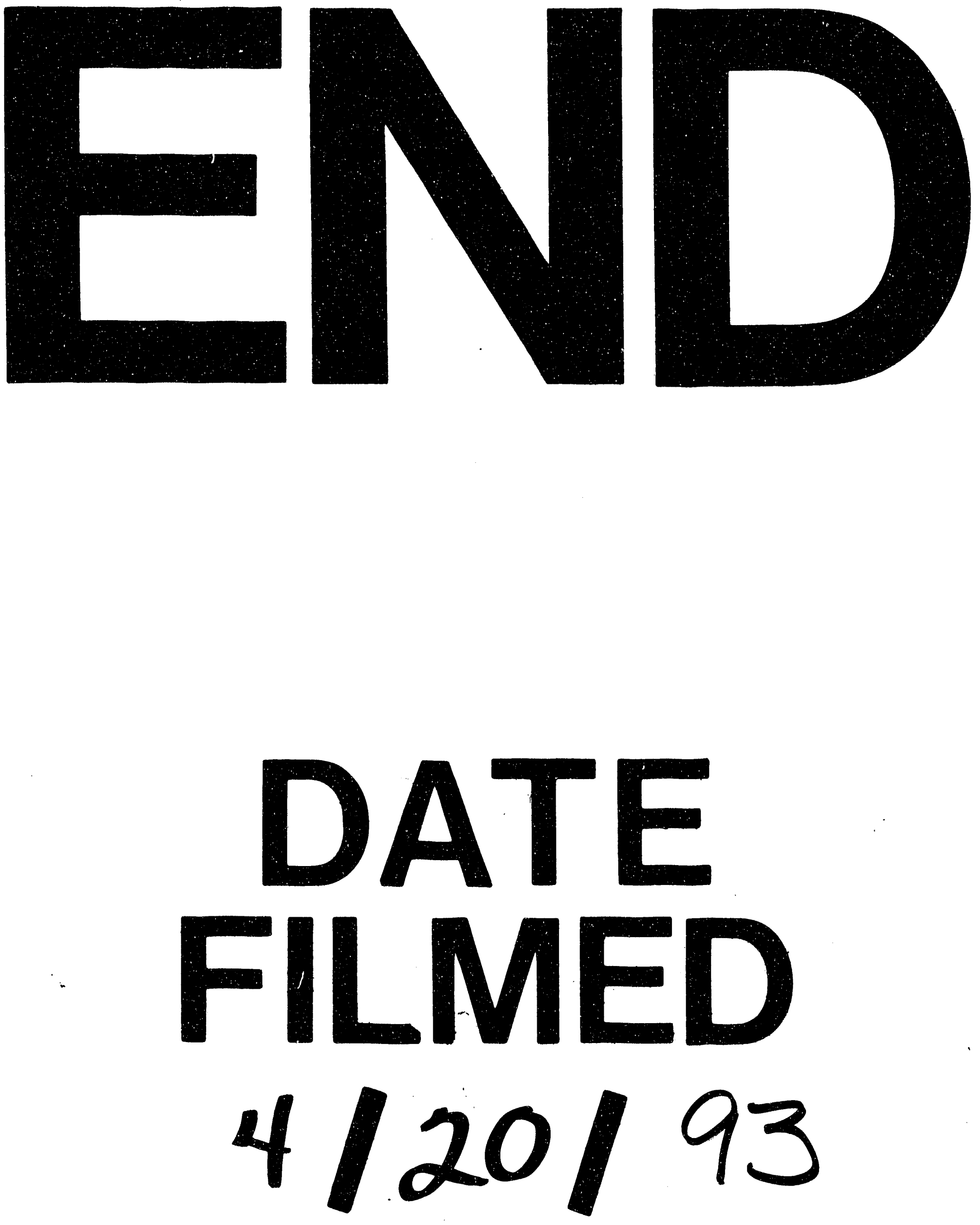

I 
